\title{
A High Degree of Dyspnea Is Associated With Poor Maximum Exercise Capacity in Subjects With COPD With the Same Severity of Air-Flow Obstruction
}

\author{
Ernesto Crisafulli, Marina Aiello, Panagiota Tzani, Antonella Ielpo, Chiara Longo, \\ Veronica Alfieri, Giuseppina Bertorelli, and Alfredo Chetta
}

\begin{abstract}
BACKGROUND: In patients with COPD, limited data have been reported concerning the association between dyspnea perception and exercise tests. Moreover, the perception of dyspnea has not been analyzed in patients with the same severity of air-flow obstruction. The aim of our study was to evaluate the relationship between the degree of dyspnea and exercise capacity in subjects with COPD who had the same severity of air-flow obstruction. METHODS: We assessed dyspnea perception and maximum exercise capacity by using the modified Medical Research Council dyspnea scale (mMRC) questionnaire and by using the symptom-limited incremental cardiopulmonary exercise test, respectively. A propensity score matching was used to obtain the balance between the subjects with COPD and with an mMRC questionnaire score $<2$ and $\geq 2$ (mMRC score) according to the severity of air-flow obstruction. RESULTS: A total of 249 ambulatory adult patients with stable COPD (mean age, $68 \mathrm{y}$ ) were considered in the full cohort. After propensity score analysis, 160 subjects $\left(65 \%\right.$ men; mean $\pm \mathrm{SD} \mathrm{FEV}_{1}, 47.5 \pm 12.8 \%$ of predicted) were included in our study cohort. The subjects with an mMRC questionnaire score $\geq 2$ in comparison with those with an mMRC questionnaire score $<2$ showed lower values in oxygen uptake at peak $\left(V_{\mathrm{O}_{2}} \max \right)(P=.002)$ and in maximum work load $(P<.001)$. In the regression models, the mMRC questionnaire score was able to predict oxygen uptake at peak $(P<.001)$ and at maximum work load $(P<.001)$. CONCLUSIONS: In subjects with COPD and with the same severity of air-flow obstruction, a high score in dyspnea was related to a poor maximum exercise capacity. Our results support the view that, in COPD, the severity of air-flow obstruction was less informative than symptoms in the combined assessment of the disease. Key words: COPD; dyspnea; cardiopulmonary exercise test; physical capacity; maximum exercise; oxygen consumption; pulmonary ventilation. [Respir Care 2019;64(4):390-397. (C) 2019 Daedalus Enterprises]
\end{abstract}

\section{Introduction}

COPD is recognized as a leading cause of death worldwide. ${ }^{1}$ Dyspnea and reduced exercise capacity usually characterize the disease. ${ }^{1}$ Dyspnea is a cardinal symptom of

\footnotetext{
The authors are affiliated with the Respiratory Disease and Lung Function Unit, Department of Medicine and Surgery, University of Parma, Parma, Italy.

The authors have disclosed no conflicts of interest.

Supplementary material related to this paper is available at http:// www.rcjournal.com.
}

patients with COPD and is considered a major cause of disability and anxiety. ${ }^{2}$ Patients with COPD frequently describe their dyspnea in different ways, such as increased breathing effort, chest tightness, unsatisfactory inspiratory effort, air hunger, or breathlessness, and the descriptors of these symptoms may vary widely both individually and

\footnotetext{
Correspondence: Ernesto Crisafulli MD PhD, Department of Medicine and Surgery, Respiratory Disease and Lung Function Unit, University of Parma, Via Rasori 10, 43126 Parma, Italy, E-mail: ernesto.crisafulli@unipr.it.
}

DOI: $10.4187 /$ respcare. 06336 
culturally. ${ }^{3}$ In patients with COPD, a simple measure of dyspnea by means of the modified Medical Research Council dyspnea scale (mMRC) questionnaire ${ }^{4}$ represents an adequate and meaningful patient-reported outcome due to the relationship with health status 5 ; moreover, a high degree of mMRC questionnaire scores were related to an increase mortality risk in these patients. ${ }^{6}$ Of note, an mMRC questionnaire score of $\geq 2$ is included in the Global Initiative for Chronic Obstructive Lung Disease guidelines ${ }^{1}$ as a threshold for separating patients with less symptomatic from patients with more symptomatic COPD.

In patients with COPD, reduced exercise capacity can result in a poor ability to perform activities of daily living; the consequent sedentary lifestyle can further worsen exercise-capacity impairment. ${ }^{7}$ In this context, the exercise capacity of patients with COPD represents an important prognostic factor, ${ }^{8}$ and, for this reason, functional evaluations, such as exercise tests, are recommended in the assessment of these patients. ${ }^{1,9}$ There is current evidence in patients with COPD that supports the association between dyspnea perception and walking capacity assessed by the 6-min walk test. ${ }^{10-13}$ There, however, is a paucity of literature regarding the correlation between dyspnea perception and standardized exercise test outcomes. ${ }^{10}$

In the present study, we hypothesized that the degree of dyspnea during activities of daily living expressed by the subjects with COPD and with the same severity of air-flow obstruction might be related to exercise capacity. Notably, the aim of our study was to ascertain whether perceived dyspnea levels were associated with poor maximum exercise capacity. Therefore, in a large cohort of subjects with COPD, we prospectively assessed dyspnea perception and maximum exercise capacity by means of the mMRC questionnaire and the symptom-limited incremental cardiopulmonary exercise test (CPET), respectively. Then, a propensity score matching program was used to obtain the balance between ambulatory subjects with COPD with an mMRC questionnaire score $<2$ and $\geq 2$ (mMRC score) according to the severity of air flow obstruction.

\section{Methods}

\section{Subjects}

We conducted this prospective, observational study at the University Hospital of Parma, Italy, over 92 months, between January 2010 and August 2017. We enrolled subjects affected by COPD, as defined according to the Global Initiative for Chronic Obstructive Lung Disease criteria, ${ }^{1}$ who were consecutively admitted to a pulmonary rehabilitation program. Inclusion criteria were as follows: body mass index $(\mathrm{BMI})<30 \mathrm{~kg} / \mathrm{m}^{2}, \mathrm{FEV}_{1}<80 \%$ of the predicted value, absence of any comorbidity that affects exercise performance (eg, anemia, neuromuscular disorders,

\section{QUICK LOOK}

\section{Current knowledge}

Dyspnea is a cardinal symptom of COPD and a modified Medical Research Council dyspnea scale questionnaire score of $\geq 2$ is considered a threshold for separating patients who are less symptomatic from those who are more symptomatic. Limited data have been reported in subjects with COPD concerning the association between patient-reported outcomes, such as dyspnea perception and exercise tests.

\section{What this paper contributes to our knowledge}

In subjects with COPD and with the same severity of air-flow obstruction, a modified Medical Research Council dyspnea scale questionnaire score of $\geq 2$ was associated with, and may predict poor, maximum exercise capacity, both in terms of maximum oxygen uptake and maximum work load, assessed by a symptomlimited incremental cardiopulmonary exercise test. Moreover, in the subjects with COPD and with the same severity of air-flow obstruction, a high dyspnea score was also associated with excess ventilation and dynamic hyperinflation during exercise and with dyspnea and leg fatigue as well as to heart rate recovery delay after exertion.

chronic cardiac failure, malignancies), ability to perform a CPET with a peak respiratory exchange ratio of $\geq 1.05$ to exclude poor motivation, and CPET stopped because of muscle fatigue and/or dyspnea. We excluded patients with COPD and a recent acute event in the $4 \mathrm{wk}$ before enrollment and patients who were on oxygen therapy. All the procedures and their risks were explained to the subjects, who gave their written informed consent to enter the study. The protocol was approved by the ethical committee of the University Hospital of Parma (approval 36215/10). All participants' data were analyzed and reported anonymously. No extramural funding was used to support the study.

\section{General Measurements}

In all the subjects, demographic characteristics (age and sex), smoking habit (current or former and number of pack-years), and the use of inhaled bronchodilators, such as a long-acting $\beta_{2}$ agonists and long-acting muscarinic antagonists, inhaled corticosteroids, and antihypertensive drugs (angiotensin-converting enzyme inhibitors, $\beta$-blockers, calcium-channel blockers, and diuretics) were recorded at enrollment. Body height and weight were measured anthropometrically. Body composition was assessed by a 
bioelectrical impedance analysis method that is based on the conductance of an electrical sinusoidal alternating current through body fluids. Foot-to-foot bioelectrical impedance analysis was measured by using a body composition analyzer (model SC-331S, Tanita, Tokyo, Japan). The fatfree mass was standardized for height, similar to BMI: fat-free mass index per height squared (in $\mathrm{kg} / \mathrm{m}^{2}$ ).

Dyspnea perception, health status impairment, and concomitant chronic diseases were measured by using the mMRC scale, the COPD assessment test, and the Charlson comorbidity index, respectively. Daily living activity related dyspnea was evaluated with the Italian version of the 5-point Medical Research Council scale dyspnea scale modified by the American Thoracic Society. ${ }^{14}$ The mMRC measures perceived breathlessness; it ranges from 1 to 5 and describes the progressive symptoms that may impact an individual with COPD: (1) shortness of breath with strenuous exercise, (2) shortness of breath when hurrying, (3) walking slower than people of the same age, (4) needing to stop after walking 100 yards on level ground, or (5) too breathless to leave the house.

The COPD assessment test is a short, easy-to-use, selfadministered questionnaire that provides a measure of the health-related impact of COPD. ${ }^{15}$ The COPD assessment test score refers to 8 items (cough, mucus production, feeling of chest tightness, dyspnea during walking a hill or climbing the stairs, home activities, confidence outside home, sleep trouble, and energy). According to the progressive weight of each item (between 0 and 5), the patient may collect a total score that ranges from 0 to 40 , in which 0 and 40 describe the absence and the maximum disease impact, respectively. The Charlson comorbidity index assigns a score to each disease that is proportional to the disease-related risk of death from the individual's selfreported comorbidities. ${ }^{16}$

\section{Lung Function}

Pulmonary function tests were performed according to international recommendations ${ }^{17}$ by using a flow-sensing spirometer and a body plethysmograph connected to a computer for data analysis (Vmax 22 and 6200, SensorMedics, Yorba Linda, California). Vital capacity, $\mathrm{FEV}_{1}$ and $\mathrm{FEV}_{1}$ to forced vital capacity (FVC) were recorded. Total lung capacity (TLC) was obtained as the sum of thoracic gas volume and linked inspiratory capacity. Diffusing capacity of the lung for carbon monoxide was measured by the single-breath method by using a mixture of carbon monoxide and methane. TLC, vital capacity, inspiratory capacity, $\mathrm{FEV}_{1}$, and the diffusing capacity of the lung for carbon monoxide were expressed as a percentage of the predicted values, which were obtained from regression equations by Quanjer et $\mathrm{al}^{18}$ and Cotes et al. ${ }^{19}$

\section{CPET}

CPET was performed according to a standardized procedure. ${ }^{20,21}$ Briefly, after calibrating the oxygen and carbon dioxide analyzers and flow mass sensor, the subjects were asked to sit on an electromagnetically braked cycle ergometer (Corival PB, Lobe Bv, Groningen, Netherlands). Breath-by-breath oxygen uptake $\left(\dot{\mathrm{V}}_{\mathrm{O}_{2}}\right.$ [in $\left.\left.\mathrm{L} / \mathrm{min}\right]\right)$, carbon dioxide production $\left(\dot{\mathrm{V}}_{\mathrm{CO}_{2}}[\right.$ in $\left.\mathrm{L} / \mathrm{min}]\right)$, tidal volume (in $\mathrm{L}$ ), and minute ventilation $\left(\grave{\mathrm{V}}_{\mathrm{E}}[\mathrm{in} \mathrm{L} / \mathrm{min}]\right)$ were collected during the test (CPX/D, Med Graphics, St. Paul, Minnesota). The subjects were continuously monitored by using a 12lead electrocardiogram (Welch Allyn CardioPerfect, Delft, The Netherlands) and a pulse oximeter (Pulse Oximeter 8600, Nonin Medical, Plymouth, Minnesota). Blood pressure was measured at 2-min intervals.

The peak work load and the maximum $\dot{\mathrm{V}}_{\mathrm{O}_{2}}$ were recorded as the mean value in watts, and $\dot{\mathrm{V}}_{\mathrm{O}_{2}}$ during the last $20 \mathrm{~s}$ of the test. $\dot{\mathrm{V}}_{\mathrm{O}_{2}}$ was expressed as an absolute value in $\mathrm{L} / \mathrm{min}$ and in $\mathrm{mL} / \mathrm{kg} / \mathrm{min}$. Anerobic threshold (in $\mathrm{mL} / \mathrm{min}$ ) was noninvasively determined by both $\mathrm{V}$-slope and ventilatory equivalents methods (dual-method approach). ${ }^{21}$ The ventilatory response to exercise was calculated as a linear regression function by plotting $\dot{\mathrm{V}}_{\mathrm{E}}$ against $\dot{\mathrm{V}}_{\mathrm{CO}_{2}}\left(\dot{\mathrm{V}}_{\mathrm{E}} / \dot{\mathrm{V}}_{\mathrm{CO}_{2}}\right.$ slope $)$. Changes in operational lung volumes were assessed every 2 min during exercise and at peak exercise. When assuming that TLC remains constant during exercise in individuals with COPD, ${ }^{22}$ changes in inspiratory capacity reflect changes in end-expiratory lung volume. The cardiovascular response to the exercise was expressed by the $\mathrm{O}_{2}$ pulse (in $\mathrm{mL} / \mathrm{beats} / \mathrm{min})^{22}$ and heart rate recovery (in beats $/ \mathrm{min}$ ). ${ }^{23}$ Dyspnea and muscle fatigue were measured at the end of the incremental exercise by using a visual analog scale (VAS). VAS dyspnea rating and VAS muscle fatigue rating were divided by the maximum work load (ie, VAS/W $\mathrm{W}_{\text {dys }}$ (Work load for dyspnea rating) and $\mathrm{VAS} / \mathrm{W}_{\text {fat }}$ (muscle fatigue rating), respectively $[\mathrm{in} \mathrm{mm} / \mathrm{W}]) .^{23}$

\section{Statistical Analysis}

A Shapiro-Wilk test was used to assess the normality of distribution. Data were reported as mean \pm SD or median (1st quartile, 3rd quartile; interquartile range) for continuous variables with normal and non-normal distribution, respectively. The number (\%) of subjects was used for categorical variables. The chi-square test or the Fisher exact test was used for the comparison of categorical variables, whereas continuous variables were analyzed with the $t$ test or the non-parametric Mann-Whitney test. For the analyses of correlation, the Pearson $r$ and the Spearman $\rho$ were used for linear or normally distributed variables and for non-linear or non-normally distributed variables, respectively. Linear regression models were performed by 


\section{DyspNea AND MAXIMUM EXERCISE CAPACITY IN COPD}

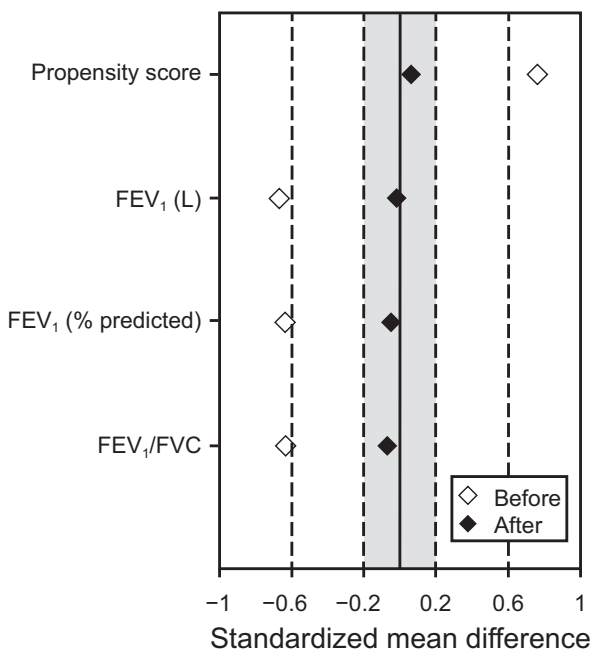

Fig. 1. Plot displaying standardized mean differences in variables concerning airflow obstruction, before and after propensity score matching.

using the mMRC questionnaire score as an independent variable to predict maximum $\dot{\mathrm{V}}_{\mathrm{O}_{2}}$ (in $\mathrm{mL} / \mathrm{kg} / \mathrm{min}$ ) and work load (in W) (dependent variables). $\mathrm{R}, \mathrm{r}^{2}, \beta$, standard error (SE), and 95\% CI for $\beta$ were calculated for each model.

A propensity score matching (PSM) program ${ }^{24}$ was used to match the 2 cohorts by using a 1:1 nearest-neighbor matching, without replacement within a caliper width of 0.2. The variables included as covariates in the PSM were the following: $\mathrm{FEV}_{1}$ (in $\mathrm{L}$ ), $\mathrm{FEV}_{1} \%$ predicted, and $\mathrm{FEV}_{1} / \mathrm{FVC}$. An allocation ratio of 1:1 was used. After matching, adequate comparability was shown by a decrease to $<20 \%(0.2)$ of the standardized mean difference $^{25}$ between the subjects with an mMRC questionnaire score $<2$ and $\geq 2$ (mMRC score) for all covariates considered (Fig. 1); moreover, an adequate model fit with discrimination and calibration of the propensity score was demonstrated by the logistic model, including covariates, yielded a goodness-of-fit $P=.73$. All statistical analyses were performed by using IBM SPSS Statistics 25.0 (Armonk, New York). A value of $P<.05$ was considered statistically significant.

\section{Results}

\section{General Characteristics}

There were 403 patients with COPD enrolled in the program at the University Hospital of Parma, Italy, between January 2010 and August 2017. From these, 249 adult subjects with stable COPD (67\% men), with a mean age of $68 \mathrm{y}$, were included in the full cohort; of these, 90 subjects (36\%) had an mMRC questionnaire score of $\geq 2$. After the propensity score, 160 subjects (50\% with an mMRC ques- tionnaire score of $<2$ and $50 \%$ with an mMRC questionnaire score of $\geq 2$ [65\% men]) represented our study cohort. The subjects were of normal weight (mean \pm SD BMI, $24.8 \pm 3.4 \mathrm{~kg} / \mathrm{m}^{2}$ ), had moderate-to-severe air-flow obstruction (mean $\pm \mathrm{SD} \mathrm{FEV}, 47.5 \pm 12.8 \%$ of predicted), a moderate static hyperinflation degree (median [1st quartile, 3rd quartile], inspiratory capacity to TLC $0.27[0.23 ; 0.32]$ ), and a low number of comorbidities (Charlson comorbidity index $1[0,2]$ score). There was no difference between the subjects with an mMRC questionnaire score $<2$ and $\geq 2$ (mMRC score) in baseline characteristics, except for COPD assessment test, higher in the group with a mean \pm SD mMRC questionnaire score $\geq 2$ $(17.1 \pm 7.3$ vs $9.6 \pm 3.9, P<.001)$. Data about general characteristics of the subjects before and after the propensity scores are reported in Table 1 and supplementary material (see the supplementary materials at http:// www.rcjournal.com).

\section{Dyspnea Perception and CPET}

With regard to CPET-related variables (Table 2), the subjects with an mMRC questionnaire score $\geq 2$ in comparison with those with an mMRC questionnaire score $<2$ had lower levels of maximum $\dot{\mathrm{V}}_{\mathrm{O}_{2}}$, peak work load, inspiratory capacity at peak, inspiratory capacity to TLC at peak, and heart rate recovery. Moreover, the same group of subjects had higher levels of $\dot{V}_{\mathrm{E}}$ to the slope of $\dot{\mathrm{V}}_{\mathrm{CO}_{2}}$, $\mathrm{VAS} / \mathrm{W}_{\mathrm{dys}}$ (Work load for dyspnea rating), and $\mathrm{VAS} / \mathrm{W}_{\text {fat }}$ (muscle fatigue rating).

In the linear regression models, the mMRC questionnaire score was able to predict variables related to the maximum exercise capacity, such as maximum $\dot{\mathrm{V}}_{\mathrm{O}_{2}}$ $\left(\mathrm{r}=0.33, \mathrm{r}^{2}=0.11, \beta=-1.45\right.$, SE $0.26, P<.001$ in the study sample before the propensity score; and $\mathrm{r}=0.28$, $\mathrm{r}^{2}=0.08, \beta=-1.18$, SE $0.31, P<.001$ after the propensity score) and the peak work load $\left(\mathrm{r}=0.41, \mathrm{r}^{2}=0.17\right.$, $\beta=-12.87$, SE $1.83, P<.001$ before the propensity score; and $\mathrm{r}=0.35, \mathrm{r}^{2}=0.12, \beta=-9.36, \mathrm{SE}=1.97$, $P<.001$ after the propensity score). In the analysis of the correlation between mMRC questionnaire scores and inspiratory capacity to TLC values at peak exercise in the cohort before and after the propensity scores, significant Spearman $\rho$ values $(\rho=-0.397, P=<.001$; and $\rho=-0.208, P=.02$ ) were obtained (Fig. 2).

\section{Discussion}

The present study showed that, in the subjects with COPD and with the same severity of air-flow obstruction, a high score in daily living activity related dyspnea evaluated by the mMRC questionnaire is associated with and may predict poor maximum exercise capacity, both in terms of maximum $\dot{\mathrm{V}}_{\mathrm{O}_{2}}$ and maximum work load, assessed by 


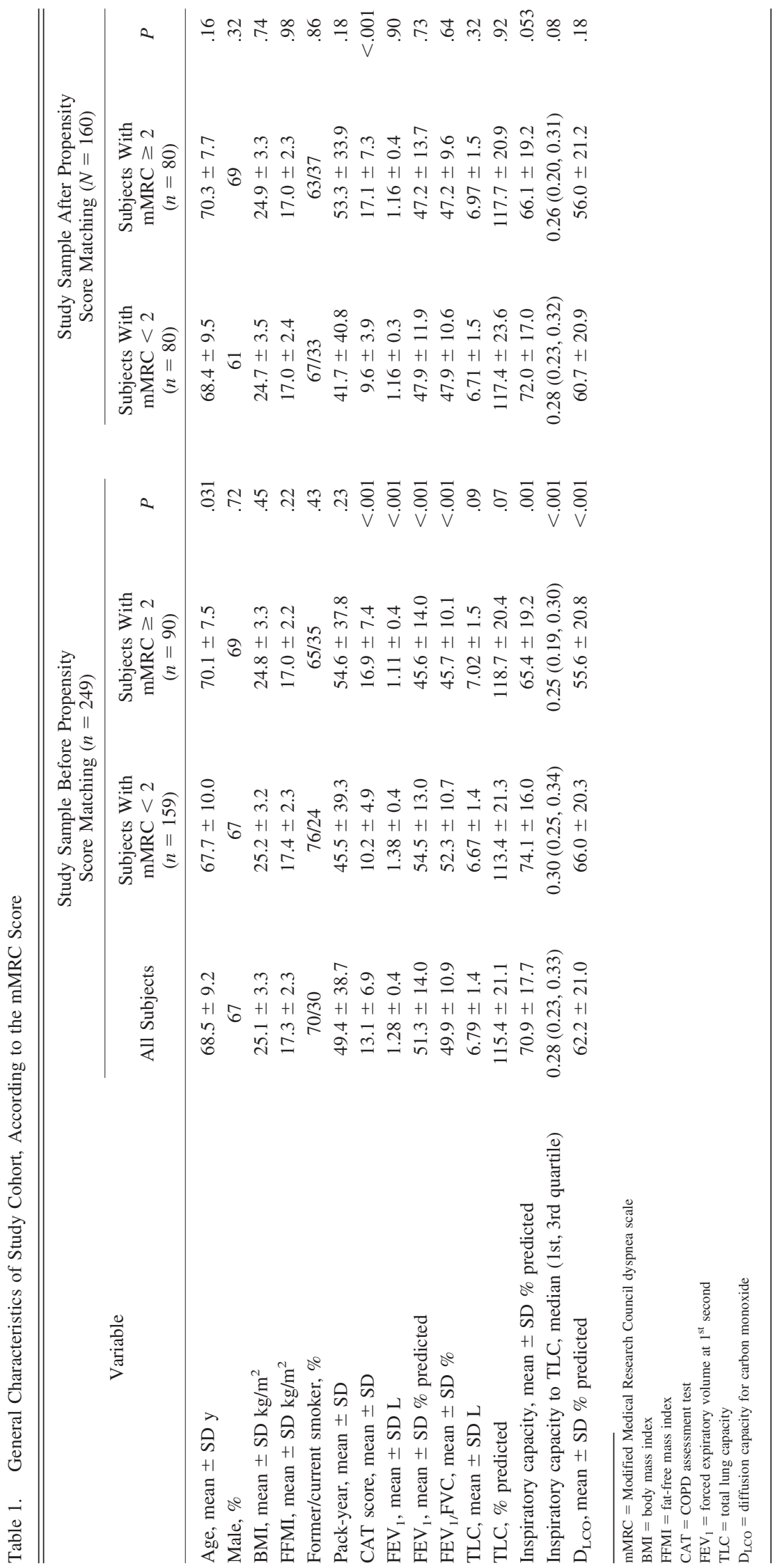




\section{Dyspnea and MaXimum EXercise CAPACITY IN COPD}

Table 2. Variables Related to Cardiopulmonary Exercise Test

\begin{tabular}{|c|c|c|c|c|}
\hline Variables & $\begin{array}{l}\text { All Subjects } \\
(N=160)\end{array}$ & $\begin{array}{l}\text { Subjects With } \\
\text { mMRC }<2 \\
(n=80)\end{array}$ & $\begin{array}{l}\text { Subjects With } \\
\text { mMRC } \geq 2 \\
(n=80)\end{array}$ & $P$ \\
\hline \multicolumn{5}{|l|}{ Maximum $\dot{\mathrm{V}}_{\mathrm{O}_{2}}$} \\
\hline Mean $\pm \mathrm{SD} \mathrm{L} / \mathrm{min}$ & $1.03 \pm 0.33$ & $1.09 \pm 0.31$ & $0.98 \pm 0.33$ & .033 \\
\hline Mean $\pm \mathrm{SD} \mathrm{mL} / \mathrm{kg} / \mathrm{min}$ & $15.1 \pm 4.1$ & $16.1 \pm 3.8$ & $14.2 \pm 4.1$ & .002 \\
\hline Peak workload, mean \pm SD W & $67.4 \pm 26.0$ & $75.4 \pm 24.5$ & $59.4 \pm 25.1$ & $<.001$ \\
\hline Anaerobic threshold, median (1st, 3rd quartile) $\%$ & $44(34,53)$ & $46(36,53)$ & $43.5(31,52.5)$ & .63 \\
\hline \multicolumn{5}{|l|}{$\mathrm{O}_{2}$ pulse, median (1st, 3rd quartile) $\mathrm{mL} / \mathrm{beat} / \mathrm{min}$} \\
\hline At rest & $3.2(2.8,4)$ & $3.3(3,4.1)$ & $3(2.4,3.9)$ & .065 \\
\hline At peak & $8.6(7,11)$ & $8.9(7.2,11)$ & $8.4(6.1,11)$ & .20 \\
\hline Inspiratory capacity at peak, mean $\pm \mathrm{SD} \%$ predicted & $58.2 \pm 15.6$ & $61.6 \pm 15.0$ & $54.8 \pm 15.5$ & .009 \\
\hline Inspiratory capacity to TLC at peak median ( $1 \mathrm{st}, 3 \mathrm{rd}$ quartile) & $0.23(0.19,0.27)$ & $0.24(0.19,0.29)$ & $0.21(0.16,0.26)$ & .034 \\
\hline \multicolumn{5}{|l|}{ SBP, median (1st, 3rd quartile) $\mathrm{mm} \mathrm{Hg}$} \\
\hline At rest & $125(110,140)$ & $120(110,140)$ & $130(110,140)$ & .72 \\
\hline At peak & $170(150,190)$ & $170(152.5,190)$ & $170(150,190)$ & .95 \\
\hline \multicolumn{5}{|l|}{ DBP, median (1st, 3rd quartile) $\mathrm{mm} \mathrm{Hg}$} \\
\hline At rest & $80(70,80)$ & $80(70,80)$ & $75(70,80)$ & .15 \\
\hline At peak & $85(80,90)$ & $85(80,95)$ & $85(80,90)$ & .60 \\
\hline \multicolumn{5}{|l|}{ Heart rate, mean $\pm \mathrm{SD}$ beats/min } \\
\hline At rest & $80.4 \pm 13.9$ & $80.1 \pm 14.8$ & $80.6 \pm 13.0$ & .82 \\
\hline At peak & $116.5 \pm 17.8$ & $118.6 \pm 18.7$ & $114.3 \pm 16.7$ & .12 \\
\hline Heart rate recovery, median (1st, 3rd quartile) & $10(4.2,14)$ & $12(6.2,18.7)$ & $8(4,12.7)$ & .002 \\
\hline$\dot{\mathrm{V}}_{\mathrm{E}}$ to slope $\dot{\mathrm{V}}_{\mathrm{CO}_{2}}$, median (1st, 3rd quartile) & $32(27.9,37)$ & $30(27,35.8)$ & $34(28,38)$ & .033 \\
\hline \multicolumn{5}{|l|}{$\mathrm{S}_{\mathrm{pO}_{2}}$, median (1st, 3rd quartile) $\%$} \\
\hline At rest & $96(94,97)$ & $96(94,97)$ & $95(93.2,96)$ & .051 \\
\hline At peak & $94(91,95.2)$ & $94(91,96)$ & $94(90,95)$ & .56 \\
\hline $\mathrm{VAS} / \mathrm{W}_{\mathrm{dys}}$ mean $\pm \mathrm{SD}^{*}$ & $1.32 \pm 0.7$ & $1.01 \pm 0.4$ & $1.62 \pm 0.9$ & $<.001$ \\
\hline $\mathrm{VAS} / \mathrm{W}_{\text {fat }}$ mean $\pm \mathrm{SD}^{*}$ & $1.22 \pm 0.9$ & $0.99 \pm 0.4$ & $1.45 \pm 1.2$ & .003 \\
\hline 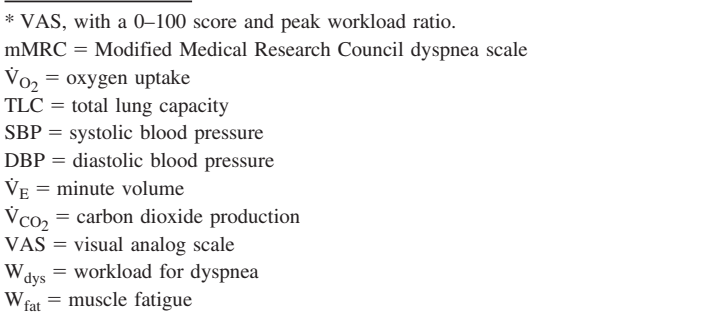 & & & & \\
\hline
\end{tabular}
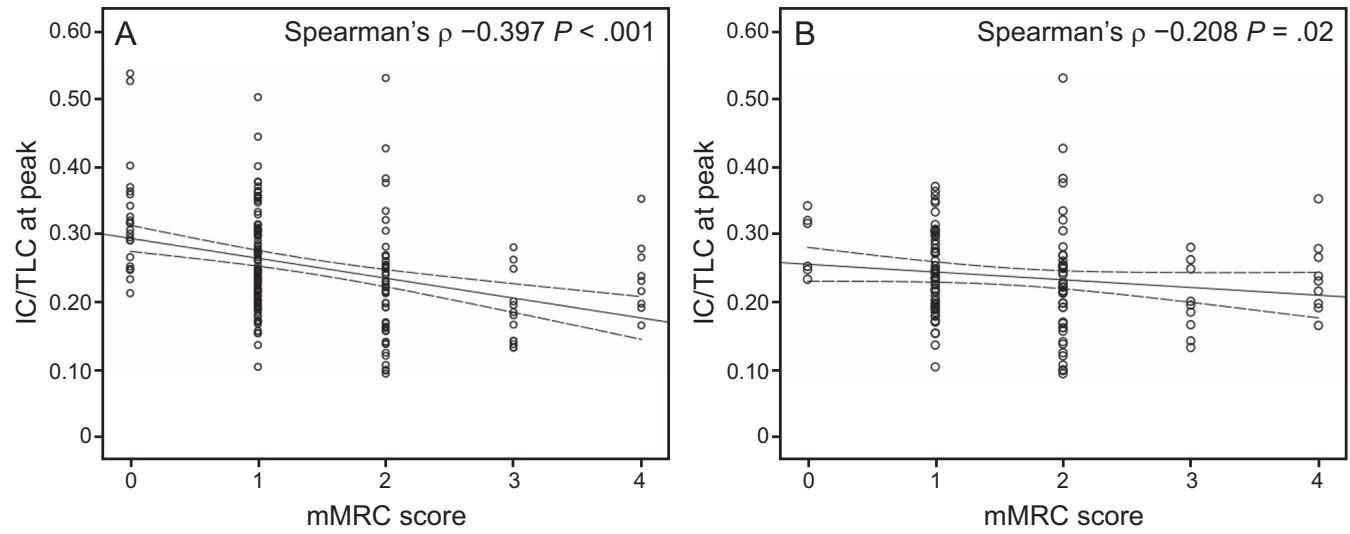

Fig. 2. Scatter plot between the modified Medical Research Council dyspnea scale (mMRC) score and inspiratory capacity/total lung capacity (IC/TLC) at peak value in the cohort of subjects before $(A)$ and after $(B)$ propensity score matching. 
symptom-limited incremental CPET. Interestingly, in the subjects with COPD and with the same severity of air-flow obstruction, we found that a high dyspnea score was also associated with high minute ventilation (VE) and dynamic hyperinflation during exercise, and with dyspnea, leg fatigue, and heart rate recovery delay after exertion.

Our main findings confirmed and extended the results from previous studies that investigated the relationship between the mMRC questionnaire score and exercise capacity in COPD. In a small group of subjects with COPD and with severe air-flow obstruction, the univariate analyses showed that the mMRC questionnaire was related to functional exercise capacity, as reflected by the 6-min walk distance. In addition, multivariate analyses showed that combining the mMRC questionnaire, $\mathrm{BMI}, \mathrm{FEV}_{1}$, quadriceps strength, and lean leg mass accounted for $76 \%$ of the variance in the 6-min walk distance. ${ }^{12}$

Further, in 62 subjects with severe COPD, a significant relationship was found between scores on some clinical dyspnea scales, including the mMRC questionnaire and the walking distance achieved in self-paced treadmill walking tests. ${ }^{11}$ In a large group of subjects with COPD, the relationship between the asymptomatic peripheral arterial disease and the walking distance assessed by the 6-min walk test, a strong and negative relationship between walking distance and the mMRC questionnaire score was found. ${ }^{13} \mathrm{Up}$ to now, only 1 study investigated the association between the mMRC questionnaire score and maximum exercise capacity in a large cohort of subjects with COPD and with a wide severity of air-flow obstruction, that the mMRC score was weakly and negatively correlated with the maximum $\dot{\mathrm{V}}_{\mathrm{O}_{2}}{ }^{8}$

However, none of these studies assessed dyspnea perception in subjects with the same severity of air-flow obstruction and, as expected, the subjects with a higher degree of dyspnea had lower lung function values and exercise capacity..$^{8,10-13}$ In the present study, we used a propensity score matching program to obtain the balance between the subjects with COPD and with an mMRC questionnaire score $<2$ and $\geq 2$ is reported for mMRC score according to the severity of air-flow obstruction. Accordingly, we provided the first evidence that a high score in daily living activity related dyspnea evaluated by the mMRC questionnaire was linked to poor maximum exercise capacity, even in subjects with the same severity of air-flow obstruction.

In the present study, dyspnea was also associated with ventilatory constraints, such as excess ventilation and dynamic hyperinflation, typically experienced as limiting factors of exercise by subjects with COPD. ${ }^{26}$ In addition, we found that the subjects who were more dyspneic by mMRC questionnaire categorization had more dyspnea after CPET. The $\dot{\mathrm{V}}_{\mathrm{E}}$ related to the carbon dioxide output may be increased in patients with COPD during exercise compared with controls. ${ }^{27}$ The subjects with COPD also showed an inverse relationship between the $\dot{\mathrm{V}}_{\mathrm{E}}$ to slope of $\dot{\mathrm{V}}_{\mathrm{CO}_{2}}$ and $\mathrm{V}_{\mathrm{O}_{2}}$ peak during a CPET. ${ }^{28}$

Furthermore, in subjects with COPD, dynamic hyperinflation on exertion may play a pivotal role in exertional breathlessness. ${ }^{29}$ Notably, during exercise, individuals with COPD may be unable to fully exhale before inspiration, with the development of worsening air-trapping, which can lead to severe mechanical and sensory consequences. The results of this study also showed that subjects with more dyspnea compared with those who were less dyspneic had a delay in heart rate recovery after maximum exercise. It is noteworthy that the median value of heart rate recovery of these subjects was $<12$ beats $/ \mathrm{min}$, which is considered a threshold value suggestive of autonomic dysfunction. ${ }^{23}$ Importantly, delayed heart rate recovery was associated with a worse prognosis in subjects with COPD. ${ }^{30}$

Our study had some limitations and strengths. The subjects included in this study were only those who attended a tertiary center and were admitted to a pulmonary rehabilitation program; therefore, they might not represent the general population of individuals with COPD. However, the range of the severity of air-flow obstruction found in our subjects was typical of patients with COPD seen by clinicians. Our study was an observational study; therefore, based on our results, we can only infer and not establish the contributing factors of exercise capacity in subjects with COPD and with dyspnea. We need further longitudinal studies on maximum exercise capacity in subjects with COPD, with varying degrees of dyspnea over time. Strengths include the large size of the study and the analysis of several variables related to the ventilatory response to exercise (ie, dynamic hyperinflation). In addition, we restricted our cohort of subjects to individuals with $\mathrm{BMI}<30 \mathrm{~kg} / \mathrm{m}^{2}$ and with $\mathrm{FEV}_{1}<80 \%$ predicted to exclude the effect of obesity on maximum exercise capacity and overdiagnosis, respectively.

\section{Conclusions}

The present study further confirmed the value of the mMRC questionnaire scale in the assessment of the daily living activity related dyspnea in patients with COPD and showed that dyspnea, a cardinal symptom of the disease, was associated with maximum exercise capacity in subjects with COPD and with the same severity of air-flow obstruction. Our results supported the view of the Global Initiative for Chronic Obstructive Lung Disease guidelines, ${ }^{1}$ which considers the severity of air-flow obstruction, as expressed as $\mathrm{FEV}_{1}$, less informative than symptoms in the combined assessment of the disease, and in making treatment decision for individualized patient care. 


\section{Dyspnea and MaXimum EXercise CAPACITY IN COPD}

\section{REFERENCES}

1. Global Strategy for the Diagnosis, Management and Prevention of COPD, Global Initiative for Chronic Obstructive Lung Disease (GOLD) 2017. http://goldcopd.org. Accessed on March 1, 2018.

2. Miravitlles M, Worth H, Soler Cataluña JJ, Price D, De Benedetto F, Roche N, et al. Observational study to characterise 24-hour COPD symptoms and their relationship with patient-reported outcomes: results from the ASSESS study. Respir Res 2014;15:122.

3. Crisafulli E, Clini EM. Measures of dyspnea in pulmonary rehabilitation. Multidiscip Respir Med 2010;5(3):202-210.

4. Fletcher CM. Standardised questionnaire on respiratory symptoms: a statement prepared and approved by the MRC Committee on the Aetiology of Chronic Bronchitis (MRC breathlessness score). Br Med J 1960 Dec 3;2(5213): 1665.

5. Bestall JC, Paul EA, Garrod R, Garnham R, Jones PW, Wedzicha JA. Usefulness of the Medical Research Council (MRC) dyspnoea scale as a measure of disability in patients with chronic obstructive pulmonary disease. Thorax 1999;54(7):581-586.

6. Nishimura K, Izumi T, Tsukino M, Oga T. Dyspnea is a better predictor of 5-year survival than airway obstruction in patients with COPD. Chest 2002;121(5):1434-1440.

7. O'Donnell DE, Gebke KB. Activity restriction in mild COPD: a challenging clinical problem. Int J Chron Obstruct Pulmon Dis 2014; 9:577-588.

8. Cote CG, Pinto-Plata V, Kasprzyk K, Dordelly LJ, Celli BR. The 6-min walk distance, peak oxygen uptake, and mortality in COPD. Chest 2007;132(6):1778-1785

9. Clini EM, Crisafulli E. Exercise capacity as a pulmonary rehabilitation outcome. Respiration 2009;77(2):121-128.

10. Punekar YS, Riley JH, Lloyd E, Driessen M, Singh SJ. Systematic review of the association between exercise tests and patient-reported outcomes in patients with chronic obstructive pulmonary disease. Int J Chron Obstruct Pulmon Dis 2017;12:2487-2506.

11. Wegner RE, Jörres RA, Kirsten DK, Magnussen H. Factor analysis of exercise capacity, dyspnoea ratings and lung function in patients with severe COPD. Eur Respir J 1994;7(4):725-729.

12. Hillman CM, Heinecke EL, Hii JW, Cecins NM, Jenkins SC, Eastwood PR. Relationship between body composition, peripheral muscle strength and functional exercise capacity in patients with severe chronic obstructive pulmonary disease. Intern Med J 2012;42(5): 578-581.

13. Sun KS, Lin MS, Chen YJ, Chen YY, Chen SC, Chen W. Is asymptomatic peripheral arterial disease associated with walking endurance in patients with COPD? Int $\mathrm{J}$ Chron Obstruct Pulmon Dis 2015; 10:1487-1492.

14. Surveillance for respiratory hazards in the occupational setting [American Thoracic Society]. Am Rev Resp Dis 1982;126(5):952-956.

15. CAT Development Steering Group. COPD Assessment Test - Healthcare Professional User Guide. http://www.catestonline.org. Accessed March 1, 2018
16. Charlson ME, Pompei P, Ales KL, MacKenzie CR. A new method of classifying prognostic comorbidity in longitudinal studies: development and validation. J Chronic Dis 1987;40(5):373-383.

17. Miller MR, Hankinson J, Brusasco V, Burgos F, Casaburi R, Coates A, et al; ATS/ERS Task Force. Standardisation of spirometry. Eur Respir J 2005;26(2):319-338.

18. Quanjer PH, Tammeling GJ, Cotes JE, Pedersen OF, Peslin R, Yernault JC. Lung volumes and forced ventilatory flows. Report Working Party Standardization of Lung Function Tests, European Community for Steel and Coal. Official Statement of the European Respiratory Society. Eur Respir J Suppl 1993;16:5-40.

19. Cotes JE, Chinn DJ, Quanjer PH, Roca J, Yernault JC. Standardization of the measurement of transfer factor (diffusing capacity). Report Working Party Standardization of Lung Function Tests, European Community for Steel and Coal Official Statement of the European Respiratory Society Eur Respir J Suppl 1993;16:41-52.

20. American Thoracic Society, American College of Chest Physicians. Statement on cardiopulmonary exercise testing. Am J Respir Crit Care Med 2003;167(2):211-277.

21. Teopompi E, Tzani P, Aiello M, Ramponi S, Andrani F, Marangio E, et al. Fat-Free Mass Depletion Is Associated With Poor Exercise Capacity Irrespective of Dynamic Hyperinflation in COPD Patients. Respir Care 2014;59(5):718-725.

22. Stubbing DG, Pengelly LD, Morse JL, Jones NL. Pulmonary mechanics during exercise in subjects with chronic airflow obstruction. J Appl Physiol 1980;49(3):511-515.

23. Cole CR, Blackstone EH, Pashkow FJ, Snader CE, Lauer MS. Heart rate recovery immediately after exercise as a predictor of mortality. N Engl J Med 1999;341(18):1351-1357.

24. Thoemmes F. Propensity score matching in SPSS. 2012; arXiv: 1201.6385 [stat. AP].

25. Ho DE, Imai K, King G, Stuart E. Matching as nonparametric preprocessing for reducing model dependence in parametric causal inference. Political Analysis 2007;15:199-236.

26. Teopompi E, Tzani P, Aiello M, Gioia MR, Marangio E, Chetta A. Excess ventilation and ventilatory constraints during exercise in patients with chronic obstructive pulmonary disease. Respir Physiol Neurobiol 2014;197:9-14.

27. O'Donnell DE, Revill SM, Webb KA. Dynamic hyperinflation and exercise intolerance in chronic obstructive pulmonary disease. Am J Respir Crit Care Med 2001;164(5):770-777.

28. Teopompi E, Tzani P, Aiello M, Ramponi S, Visca D, Gioia MR, et al. Ventilatory response to carbon dioxide output in subjects with congestive heart failure and in patients with COPD with comparable exercise capacity. Respir Care 2014;59(7):1034-1041.

29. O'donnell DE. Dynamic hyperinflation and its clinical implication in COPD. Rev Mal Respir 2008;25(10):1305-1318.

30. Lacasse M, Maltais F, Poirier P, Lacasse Y, Marquis K, Jobin J, LeBlanc P. Post-exercise heart rate recovery and mortality in chronic obstructive pulmonary disease. Respir Med 2005;99(7):877-886.

This article is approved for Continuing Respiratory Care Education credit. For information and to obtain your CRCE

(free to AARC members) visit www.rcjournal.com

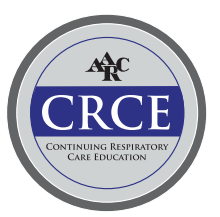

